\title{
HUBUNGAN STATUS PEKERJAAN DAN PENGETAHUAN IBU TENTANG POSYANDU BALITA DENGAN KEPATUHAN KUNJUNGAN POSYANDU DI POSYANDU BALITA SINGOSARI KELURAHAN BANYUANYAR SURAKARTA TAHUN 2018
}

\author{
The Relationship Between Mother's Occupational Status And Knowledge About \\ Posyandu Balita With Compliance Of Visiting Posyandu At Posyandu Balita Singosari \\ Kelurahan Banyuanyar Surakarta \\ Christiani Bumi Pangesti ${ }^{1}$, Wahyu Dwi Agussafutri ${ }^{2}$ \\ STIKES Kusuma Husada Surakarta \\ (christinbumi@yahoo.co.id)
}

\begin{abstract}
ABSTRAK
Latar belakang : Posyandu merupakan salah satu bentuk Upaya Kesehatan Bersumberdaya Masyarakat (UKBM) yang dikelola dari, oleh, untuk, dan bersama masyarakat, guna memberdayakan masyarakat dan memberikan kemudahan kepada masyarakat dalam memperoleh pelayanan kesehatan dasar. Dampak yang dialami balita apabila ibu tidak aktif dalam kegiatan penimbangan di Posyandu antara lain tidak mendapat penyuluhan kesehatan, tidak mendapat vitamin A, ibu balita tidak mengetahui pertumbuhan dan perkembangan berat badan balita, ibu balita tidak mendapatkan pemberian dan penyuluhan tentang makanan tambahan (PMT). Hal tersebut yang memicu munculnya permasalahan gizi pada balita yang akan berdampak sangat fatal yaitu dapat menyebabkan kematian. Fenomena yang terjadi saat ini adalah berdasarkan studi pendahuluan, tidak semua ibu patuh untuk berkunjung keposyandu setiap bulannya.

Tujuan penelitian ini untuk mengetahui hubungan status pekerjaan dan pengetahuan ibu tentang posyandu dengan kepatuhan kunjungan posyandu balita.

Metode : Penelitian ini menggunakan survey analitik dengan rancangan Cross Sectional. Pengambilan sampel dilakukan secara aksidental sampling dengan analisis data regresi logistic ganda.

Hasil : Uji Wald dijelaskan terdapat hubungan antara status pekerjaan dengan kepatuhan kunjungan ke Posyandu Balita dan secara statistik signifikan ( $\mathrm{p}=$ 0,022). Ada hubungan antara pengetahuan ibu tentang Posyandu dengan kepatuhan kunjungan ke Posyandu Balita dan secara statistik signifikan ( $\mathrm{p}=$ 0,010).

Simpulan : Ada hubungan antara status pekerjaan dan pengetahuan ibu tentang Posyandu balita dengan kepatuhan kunjungan Posyandu di Posyandu balita Singosari Kelurahan Banyuanyar Surakarta tahun 2018.
\end{abstract}

Kata Kunci : Status Pekerjaan, Pengetahuan Ibu, Kepatuhan Kunjungan Posyandu

Hubungan Status Pekerjaan Dan Pengetahuan Ibu Tentang Posyandu Balita Dengan Kepatuhan Kunjungan Posyandu Di Posyandu Balita Singosari Kelurahan Banyuanyar Surakarta (Christiani Bumi Pangesti, Wahyu Dwi Agussafutri) 


\begin{abstract}
Introduction: Posyandu is a form of Community Resource Health Effort (UKBM) which is managed from, by, for and with the community, to empower and provide facilities them in obtaining basic health services. The impact on toddlers when mothers are not active in weighing activities in the Posyandu e.g. does not get health education, does not get vitamin A, mothers do not know the growth and development of underweight children, mothers do not get information and counseling about supplementary food (PMT). This condition causes nutritional problems in toddlers which have a fatal impact that can cause death. The current phenomenon is that not all mothers are willing to visit the Posyandu every month. The purpose of this study was to determine the relationship between mothers' occupational status and knowledge about Posyandu with the compliance of Posyandu visits.

Method: This study used an analytical survey with Cross-Sectional design. Sampling was done by accidental sampling with multiple logistic regression data analysis.

Results: Wald test showed that there was a relationship between occupational status and compliance to visit Posyandu Balita and was statistically significant ( $p$ $=0.022$ ). There was a relationship between mothers' knowledge about Posyandu and compliance to visit Posyandu Balita and statistically significant $(p=0.010)$.

Conclusion: There was a relationship between mothers' occupational status and knowledge with compliance to visit Posyandu at Posyandu Balita Singosari Kelurahan Banyuanyar Surakarta 2018.
\end{abstract}

Keywords: Occupational Status, Mother's Knowledge, Compliance of Visiting Posyandu

\title{
PENDAHULUAN
}

Anak dapat tumbuh dan berkembang secara optimal merupakan harapan setiap orangtua. Pertumbuhan balita dipengaruhi oleh faktor keturunan, faktor gizi, kemampuan orang tua (sosial-ekonomi), faktor kelamin, dan faktor ras/suku bangsa. Badan kesehatan dunia WHO (World Health Organization) pada tahun 2014 memperkirakan terdapat 51 juta balita mengalami masalah gizi. Kematian balita akibat masalah gizi sebesar 2,8 juta jiwa. Masalah gizi tertinggi terjadi di Negara Afrika dan Asia Timur termasuk Indonesia. Menurut data hasil Demografi dan Kesehatan Indonesia (SDKI) tahun 2012, Angka Kematian Balita (AKABA) sebesar 40 kematian/1000 kelahiran hidup (Badan Pusat Statistik, 2013).

Status gizi anak balita dapat diukur berdasarkan umur, berat badan, dan tinggi badan. Pemantauan pertumbuhan balita sangat penting dilakukan untuk mengetahui status gizi dan apabila adanya gangguan pertumbuhan (growth faltering) secara dini. Untuk mengetahui pertumbuhan tersebut, penimbangan balita setiap bulan sangat diperlukan. Penimbangan balita dapat dilakukan diberbagai tempat seperti Posyandu, Polindes, Puskesmas atau sarana kesehatan yang lain. Pemantauan pertumbuhan balita yang dilakukan setiap bulan berdasarkan Riset Kesehatan Dasar (Riskeesdas) Tahun 2013 menunjukkan

Hubungan Status Pekerjaan Dan Pengetahuan Ibu Tentang Posyandu Balita Dengan Kepatuhan Kunjungan Posyandu Di Posyandu Balita Singosari Kelurahan Banyuanyar Surakarta (Christiani Bumi Pangesti, Wahyu Dwi Agussafutri) 
bahwa presentase balita umur 6-59 bulan yang tidak pernah ditimbang dalam enam bulan terakhir cenderung meningkat dari 25,5 persen (2007), 23,8 persen (2010) menjadi 34,3 persen (2013) (Kemenkes RI, 2013). Hasil penelitian (Sugiyarti,dkk tahun 2014) tentang kepatuhan kunjungan posyandu dan status gizi balita didapatkan hasil adanya hubungan antara tingkat kepatuhan kunjungan posyandu dengan status gizi balita di Posyandu Karangbendo Yogyakarta dengan hasil Z hitung $0,614 \geq \mathrm{Z}$ tabel 0,185 .

Posyandu merupakan salah satu bentuk Upaya Kesehatan Bersumberdaya Masyarakat (UKBM) yang dikelola dari, oleh, untuk, dan bersama masyarakat, guna memberdayakan masyarakat dan memberikan kemudahan kepada masyarakat dalam memperoleh pelayanan kesehatan dasar. Kegiatan posyandu terdiri dari kegiatan utama dan kegiatan pengembangan/pilihan. Kegiatan utama mencakup kesehatan ibu dan anak, keluarga berencana, imunisasi, gizi, dan pencehagan serta penanggulangan diare. Sedangkan untuk kegiatan pengembangan, masyarakat dapat menambah kegiatan baru disamping lima kegiatan utama yang telah ditetapkan, misalnya Bina Keluarga Balita, Tanaman Obat Keluarga, Bina Keluarga Lansia (Kemenkes RI, 2012).

Dampak yang dialami balita apabila ibu tidak aktif dalam kegiatan penimbangan di Posyandu antara lain tidak mendapat penyuluhan kesehatan, tidak mendapat vitamin A, ibu balita tidak mengetahui pertumbuhan dan perkembangan berat badan balita, ibu balita tidak mendapatkan pemberian dan penyuluhan tentang makanan tambahan (PMT). Hal tersebut yang memicu munculnya permasalahan gizi pada balita yang akan berdampak sangat fatal yaitu dapat menyebabkan kematian (Kemenkes RI, 2012).

Fenomena yang terjadi saat ini adalah berdasarkan studi pendahuluan, tidak semua ibu patuh untuk berkunjung keposyandu setiap bulannya. Ketidakpatuhan ibu di sebabkan oleh faktor yang mempengaruhi perilaku masyarakat dari faktor internal yaitu pengetahuan, sikap, persepsi, kepercayaan/keyakinan, pekerjaan, keinginan, niat, nilai, umur, dan jenis kelamin. Sedangkan dari faktor eksternal yaitu pengalaman, fasilitas. Berdasarkan data dan hal tersebut diatas peneliti tertarik untuk melakukan penelitian dengan judul "Hubungan Status Pekerjaan dan Pengetahuan Ibu tentang Posyandu terhadap Kepatuhan Kunjungan Posyandu Balita di Posyandu Balita Singosari Kelurahan Banyuanyar".

\section{METODE PENELITIAN}

Penelitian ini merupakan penelitian survey analitik dengan rancangan Cross Sectional Study yaitu suatu rancangan penelitian yang mempelajari dinamika korelasi antara sebab dengan akibat pada saat yang bersamaan. Populasi target dalam penelitian ini adalah ibu yang mempunyai balita (usia 1-5 tahun) di Posyandu Balita Singosari Banyuanyar Surakarta sebanyak 93 ibu balita dan populasi terjangkau atau rata -rata per bulan jumlah balita yang datang ke posyandu sejumlah 48 balita. Pegambian sampel dalam penelitian ini dengan menggunakan teknik aksidental sampling. Penentuan besar sampel dengan menggunakan rumus : ${ }_{n}=\frac{\mathrm{N}}{1+N(d)^{2}}$ didapatkan besar sampel sejumlah 43 responden pada bulan Maret 2018.

Hubungan Status Pekerjaan Dan Pengetahuan Ibu Tentang Posyandu Balita Dengan Kepatuhan Kunjungan Posyandu Di Posyandu Balita Singosari Kelurahan Banyuanyar Surakarta (Christiani Bumi Pangesti, Wahyu Dwi Agussafutri) 
Pada penelitian ini menggunakan alat pengumpul data berupa kuesioner. Uji validitas dilakukan di Posyandu Balita Kencana dengan responden sebanyak 30 orang dengan 20 pertanyaan. Rentang hasil uji validitas yaitu 0,435-0,682 dan 20 pertanyaan dinyatakan valid dan hasil uji reliabilitas 0,863 lebih besar dari $r_{\text {kriteria. }}$ Dalam penelitian ini pengumpulan data primer dilakukan dengan membagikan kuesioner secara langsung kepada responden, sedangkan pengumpulan data sekunder dilakukan dengan cara melihat dokumen atau catatan di buku Kesehatan Ibu dan Anak (KIA) atau kartu posyandu yang mendukung data penelitian. Analisa data dalam penelitian ini menggunakan Regresi Logistik Ganda.

\section{HASIL DAN PEMBAHASAN}

Tabel 1 Deskripsi Umur Responden

\begin{tabular}{ccc}
\hline Umur & Jumlah & Persentase $(\%)$ \\
\hline$<20$ tahun & 3 & 7.0 \\
$20-35$ tahun & 38 & 88.4 \\
$>35$ tahun & 2 & 4.6 \\
\hline Jumlah & 43 & 100 \\
\hline
\end{tabular}

Berdasarkan Tabel 1. dapat dilihat bahwa hasil bahwa mayoritas responden berusia antara 20-35 tahun yaitu sebanyak 38 orang $(88,4 \%)$.

Tabel 2. Deskripsi Pendidikan Responden

\begin{tabular}{lccc}
\hline & Pendidikan & Jumlah & Persentase (\%) \\
\hline SD & 3 & 7.0 \\
SMP & 9 & 20.9 \\
SMA & 21 & 48.8 \\
PT & 10 & 23.3 \\
\hline & Jumlah & 43 & 100 \\
\hline
\end{tabular}

Berdasarkan Tabel 2. diatas menunjukkan bahwa mayoritas responden mempunyai tingkat pendidikan SMA yaitu sebanyak 21 orang $(48,8 \%)$.

Tabel 3. Deskripsi Status Pekerjaan Responden

\begin{tabular}{|c|c|c|}
\hline Status Pekerjaan & Jumlah & Persentase (\%) \\
\hline Tidak Bekerja (IRT) & 23 & 53,5 \\
\hline Bekerja & 20 & 46,5 \\
\hline Jumlah & 43 & 100 \\
\hline
\end{tabular}

Tabel 3 diatas menunjukkan bahwa mayoritas responden adalah tidak bekerja atau sebagai ibu rumah tangga yaitu sebanyak 23 orang $(53,5 \%)$.

Hubungan Status Pekerjaan Dan Pengetahuan Ibu Tentang Posyandu Balita Dengan Kepatuhan Kunjungan Posyandu Di Posyandu Balita Singosari Kelurahan 
Tabel 4. Pengetahuan Ibu Tentang Posyandu

\begin{tabular}{|c|c|c|}
\hline Pengetahuan & Jumlah & Persentase (\%) \\
\hline Kurang baik & 13 & 30.2 \\
\hline Baik & 30 & 69.8 \\
\hline Jumlah & 43 & 100 \\
\hline
\end{tabular}

Berdasarkan tabel 4 menunjukkan bahwa mayoritas responden mempunyai pengetahuan yang baik tentang Posyandu yaitu sebanyak 30 orang $(69,8 \%)$.

Tabel 5. Kepatuhan Kunjungan ke Posyandu

\begin{tabular}{|c|c|c|}
\hline Kepatuhan & Jumlah & Persentase (\%) \\
\hline Tidak patuh & 9 & 20,9 \\
\hline Patuh & 34 & 79,1 \\
\hline Jumlah & 43 & 100 \\
\hline
\end{tabular}

Berdasarkan tabel 5 menunjukkan bahwa mayoritas responden patuh dalam kunjungan ke Posyandu Balita yaitu sebanyak 34 orang $(79,1 \%)$.

Tabel 6. Hubungan Status Pekerjaan Ibu dan Pengetahuan Ibu tentang Posyandu dengan Kepatuhan Kunjungan Posyandu Balita

\begin{tabular}{lcccc}
\hline \multirow{2}{*}{ Variabel } & Exp (B) & \multicolumn{2}{c}{ CI 95\% } & p Uji \\
\cline { 3 - 4 } & (OR) & Batas bawah & Batas atas & Wald \\
\hline Status Pekerjaan & 2.525 & .005 & .663 & .022 \\
Pengetahuan & 3.425 & 2.125 & 8.729 & .010 \\
N observasi & 43 & & & \\
Nagelkerke R $^{2}$ & $44,9 \%$ & & & \\
\hline
\end{tabular}

Berdasarkan tabel 6 menunjukkan nilai Odd Ratio variabel status pekerjaan sebesar 2,525 berarti bahwa ibu yang tidak bekerja mempunyai kemungkinan 2,52 kali lebih besar untuk patuh dalam kunjungan ke Posyandu Balita daripada ibu yang bekerja. Hasil uji wald menunjukkan bahwa ada hubungan antara status pekerjaan dengan kepatuhan kunjungan ke Posyandu Balita dan secara statistik signifikan $(\mathrm{p}=0,022)$. Nilai Odd Ratio variabel pengetahuan tentang Posyandu sebesar 3,42 berarti bahwa ibu yang mempunyai pengetahuan baik tentang Posyandu mempunyai kemungkinan 3,42 kali lebih besar untuk patuh dalam kunjungan Posyandu Balita daripada ibu yang mempunyai pengetahuan kurang baik tentang Posyandu Balita. Hasil uji wald menunjukkan bahwa ada hubungan antara pengetahuan ibu tentang Posyandu dengan kepatuhan kunjungan ke Posyandu Balita dan secara statistik signifikan (p $=0,010)$. Nilai Negelkerke $\mathrm{R}^{2}$ sebesar $44,9 \%$ berarti bahwa variabel hubungan status pekerjaan ibu dan pengetahuan ibu tentang Posyandu mampu menjelaskan kepatuhan kunjungan posyandu balita sebesar 44,9\% dan sisanya yaitu sebesar $55,1 \%$ dijelaskan oleh faktor lain diluar model penelitian.

Hubungan Status Pekerjaan Dan Pengetahuan Ibu Tentang Posyandu Balita Dengan Kepatuhan Kunjungan Posyandu Di Posyandu Balita Singosari Kelurahan 
Hasil penelitian menunjukkan bahwa mayoritas responden berusia antara 20-35 tahun yaitu sebanyak 38 orang (88,4\%). Menurut Hutami dan Ardianto (2015), kepatuhan kunjungan balita ke Posyandu dapat dipengaruhi oleh beberapa hal seperti usia, pengetahuan dan pekerjaan orang tua. Tingkat kematangan seseorang akan lebih matang dalam berpikir seiring dengan bertambahnya usia. Semakin dewasa seseorang, maka cara berpikir semakin matang.

Mayoritas responden mempunyai tingkat pendidikan SMA yaitu sebanyak 21 orang $(48,8 \%)$. Pendidikan ibu berhubungan dengan kunjungan ibu balita ke Posyandu. Dalam penelitian ini masih terdapat ibu yang memiliki pendidikan rendah yakni tamat SD dan SMP hal tersebut dapat mempengaruhi pengetahuannya. Ibu yang memiliki pendidikan rendah cenderung memiliki pengetahuan yang kurang, sehingga tinggi rendahnya pendidikan seseorang akan dapat mempengaruhi pengetahuannya.

Murwati dan Lestari (2009) menyatakan bahwa ibu-ibu dengan pendidikan yang lebih tinggi, lebih sering menimbangkan balitanya ke posyandu. Hal ini disebabkan oleh faktor kebutuhan para pasien atau pengguna pelayanan kesehatan terhadap pentingnya pelayanan kesehatan bagi dirinya atau bagi keluarganya. Hasil ini sesuai dengan penelitian dari Reihana dan Duarsa (2012) bahwa pendidikan ibu yang tinggi mempunyai peluang 2,7 kali untuk berpartisipasi aktif menimbang balitanya ke Posyandu dibanding ibu yang berpendidikan rendah. Semakin tinggi pendidikan, tentunya seseorang akan semakin berkemampuan atau kompeten. Dengan demikian, semakin tinggi pendidikan, kegiatan kemasyarakatan akan semakin tinggi.

Mayoritas responden adalah tidak bekerja atau sebagai ibu rumah tangga yaitu sebanyak 23 orang $(53,5 \%)$. Kerja merupakan suatu yang dibutuhkan oleh manusia. Aspek sosio ekonomi akan berpengaruh pada partisipasi masyarakat di posyandu. Semua ibu yang bekerja baik di rumah atau luar rumah, keduanya akan tetap meninggalkan anak-anaknya untuk sebagian besar waktu (Niven, 2002).

Pekerjaan memiliki hubungan dengan pendidikan dan pendapatan serta berperan penting dalam kehidupan sosial ekonomi dan berkitan dengan faktor lain seperti kesehatan. Hal tersebut sesuai menurut Khomsan (2007) bahwa seseoang yang mempunyai pekerjaan dengan waktu yang cukup padat akan mempengaruhi ketidakhadiran dalam pelaksanaan Posyandu. Orang tua yang bekerja akan tidak mempunyai waktu luang, sehingga dapat disimpulkan bahwa semakin tinggi aktivitas pekerjaan orang tua semakin sulit datang ke Posyandu.

Mayoritas responden mempunyai pengetahuan yang baik tentang Posyandu yaitu sebanyak 30 orang $(69,8 \%)$. Hasil tersebut menunjukkan bahwa sebagian besar pengetahuan yang dimiliki responden dalam kategori baik dan dimana pengetahuan yang dimiki ibu dapat mempengaruhi perilaku kesehatannya. Pengetahuan ibu yang baik maka akan mempermudah dan lebih memahami akan pentingnya kegiatan posyandu pada balitanya. Sesorang yang berpengetahuan baik dapat lebih memelihara tingkat kesehatannya daripada seseorang yang berpengetahuan kurang.

Hasil penelitian menunjukkan bahwa mayoritas responden patuh dalam kunjungan ke Posyandu Balita yaitu sebanyak 34 orang $(79,1 \%)$. Sakbaniyah, dkk

Hubungan Status Pekerjaan Dan Pengetahuan Ibu Tentang Posyandu Balita Dengan Kepatuhan Kunjungan Posyandu Di Posyandu Balita Singosari Kelurahan Banyuanyar Surakarta (Christiani Bumi Pangesti, Wahyu Dwi Agussafutri) 
(2013) menyatakan bahwa kepatuhan merupakan kepatuhan pasien sejauhmana perilaku pasien tersebut sesuai dengan ketentuan yang diberikan oleh petugas kesehatan. Hasil tersebut menunjukkan bahwa ibu telah mengetahui pentingnya melakukan posyandu secara rutin pada balita setiap bulannya.

Sikap patuh yang berarti disiplin dan taat tersebut dipengaruhi oleh faktorfaktor antara lain pemahaman tentang instruksi yang diberikan oleh petugas, kualitas interaksi antara petugas kesehatan dan pasien, isolasi sosial dan keluarga yang dapat menjadi faktor pengaruh dalam menentukan nilai kesehatan setiap individu, keyakinan, sikap dan kepribadian. Orang-orang yang tidak patuh adalah orang yang mengalami depresi, memiliki ego yang lebih lemah dan kehidupan sosialnya lebih memusatkan perhatian pada diri sendiri. Banyaknya ibu yang patuh dalam melakukan kunjungan ke posyandu dalam penelitian ini, dapat dipengaruhi oleh baiknya pengetahuan yang dimilki, dimana pengetahuan dapat mempengaruhi pola pikir dan pemahaman dari informasi yang diterimanya (Sakbaniyah, dkk, 2013).

Hasil penelitian menunjukkan bahwa ada hubungan antara status pekerjaan dengan kepatuhan kunjungan ke Posyandu Balita dan secara statistik signifikan. Hasil penelitian ini mendukung penelitian Handayani (2012) bahwa faktor status pekerjaan dapat mempengaruhi kunjungan ibu balita ke Posyandu, dimana diketahui bahwa sebagian besar responden yang melakukan adalah ibu yang berprofesi sebagai ibu rumah tangga. Hal ini menunjukkan bahwa kunjungan ibu rumah tangga cukup teratur daripada kunjungan ibu yang bekerja, karena ibu rumah tangga memiliki waktu lebih banyak di rumah sehingga mereka lebih memperhatikan status perkembangan balitanya dengan cara memeriksakan ke Posyandu. Posyandu biasa diselenggarakan pada hari kerja dan jam kerja. Kegiatan Posyandu diselenggarkan mulai jam 09.00 s/d 12.00 WIB, sehingga ibu bekerja tidak dapat membawa anaknya ke Posyandu. Selain itu mereka merasa mampu membawa anak sakit langsung ke praktek dokter, sehingga menganggap tidak perlu dibawa ke Posyandu untuk penimbangan.

Hasil penelitian menunjukkan bahwa ada hubungan antara pengetahuan ibu tentang Posyandu dengan kepatuhan kunjungan ke Posyandu Balita dan secara statistik signifikan $(\mathrm{p}=0,010)$. Pengetahuan yang dimiliki ibu merupakan dasar untuk berbuat, karena itu kemampuan seseorang melakukan sesuatu tergantung pengetahuan yang ia miliki. Dasar pengetahuan tentang posyandu, tujuan, dan manfaat yang diperoleh di Posyandu memungkinkan ibu untuk hadir pada setiap pelaksanaan Posyandu (Mubarak, 2007).Hasil ini mendukung penelitian terdahulu dari Reihana dan Duarsa (2012) bahwa pengetahuan ibu berhubungan dengan kunjungan ibu menimbang balitanya ke Posyandu. Apabila penerimaan perilaku melalui proses yang didasari oleh pengetahuan, kesadaran dan sikap yang positif maka perilaku tersebut akan bersifat langgeng. Sebaliknya apabila perilaku itu tidak didasari oleh pengetahuan dan kesadaran maka akan tidak langgeng. Oleh karena itu pengetahuan ibu harus terus ditingkatkan sehingga pengetahuan dapat meningkat. Pengetahuan ini dapat dilaksanakan melalui penyuluhan-penyuluhan yang berkesinambungan baik melalui leaflet, poster dan dapat pula lewat radio.

Pengetahuan tentang posyandu akan membantu orang tua dalam memanfaatkan posyandu. Seorang ibu dengan pengetahuan yang mencukupi akan

Hubungan Status Pekerjaan Dan Pengetahuan Ibu Tentang Posyandu Balita Dengan Kepatuhan Kunjungan Posyandu Di Posyandu Balita Singosari Kelurahan Banyuanyar Surakarta (Christiani Bumi Pangesti, Wahyu Dwi Agussafutri) 
meningkatkan kesadaran tentang pemanfaatan sarana kesehatan khususnya untuk memantau kesehatan balitanya, sehingga angka kunjungan balita ke posyandu semakin tinggi atau menyebabkan kunjungan menjadi rutin.

\section{SIMPULAN DAN SARAN}

\section{Simpulan}

Mayoritas responden berusia antara 20-35 tahun yaitu sebanyak 38 orang $(88,4 \%)$ dengan tingkat pendidikan SMA yaitu sebanyak 21 orang $(48,8 \%)$. Mayoritas responden adalah tidak bekerja atau sebagai ibu rumah tangga yaitu sebanyak 23 orang $(53,5 \%)$ dan mempunyai pengetahuan yang baik tentang Posyandu yaitu sebanyak 30 orang $(69,8 \%)$ serta patuh dalam kunjungan ke Posyandu Balita yaitu sebanyak 34 orang $(79,1 \%)$. Ada hubungan antara status pekerjaan dengan kepatuhan kunjungan ke Posyandu Balita dan secara statistik signifikan $(\mathrm{p}=0,022)$. Ada hubungan antara pengetahuan ibu tentang Posyandu dengan kepatuhan kunjungan ke Posyandu Balita dan secara statistik signifikan ( $\mathrm{p}$ $=0,010)$.

\section{Saran}

Bagi Masyarakat, ibu yang memiliki frekuensi kunjungan di Posyandu dengan kriteria baik agar tetap dipertahankan, sedangkan untuk ibu yang memiliki frekuensi kunjungan di Posyandu dengan kriteria kurang baik disarankan untuk meningkatkan kunjungan ke Posyandu setiap sebulan sekali agar status kesehatan balitanya dapat terpantau dengan baik. Bagi Posyandu, Posyandu melalui kadernya diharapkan dapat meningkatkan kualitas pelayanan kesehatan Posyandu melalui penyuluhan kesehatan yang bekerjasama dengan petugas kesehatan Puskesmas, pemeriksaan kesehatan oleh petugas Puskesmas setiap sebulan sekali, konseling agar ibu-ibu balita termotivasi untuk melakukan kunjungan ke Posyandu sehingga status kesehatan balita dapat terpantau dengan baik. Selain itu, kualitas pelayanan kesehatan Posyandu dapat ditingkatkan melalui menjalin hubungan yang baik dengan ibu-ibu balita misalnya melalui komunikasi yang efektif, mengajak ibu-ibu untuk mengikuti kegiatan Posyandu, dan meningkatkan kompetensi teknis dari kader-kader Posyandu. Bagi peneliti selanjutnya, hendaknya penelitian selanjutnya melakukan penelitian lanjutan tentang faktorfaktor lain yang berhubungan dengan kepatuhan kunjungan ke Posyandu balita dan juga mengembangkan penelitian dengan metode mix method.

\section{DAFTAR PUSTAKA}

Badan Pusat Statistik. 2013. Survei Demografi dan Kesehatan Indonesia (SDKI) 2012. BPS-BKKBN-Depkes-ORC Macro Calverton (USA). Jakarta : SDKI 2012

Handayani, R.N.F. 2012. Hubungan Antara Kualitas Pelayanan Kesehatan Posyandu dengan Frekuensi Kunjungan Ibu Balita di Posyandu XI Serangan Sidoluhur Godean Sleman Yogyakarta. Naskah Publikasi.

Hubungan Status Pekerjaan Dan Pengetahuan Ibu Tentang Posyandu Balita Dengan Kepatuhan Kunjungan Posyandu Di Posyandu Balita Singosari Kelurahan 
Program Studi Ilmu Keperawatan Sekolah Tinggi Ilmu Kesehatan ‘Aisyiyah Yogyakarta

Hutami IS dan Ardianto E. 2015. Faktor yang Berhubungan dengan Kunjungan Balita di Posyandu Desa Bulak Lor Wilayah Kerja Puskesmas Jatibarang. Jurnal Kesehatan Masyarakat. Vo. 1. No. 2. Agustus 2015. FKM. Universitas Wiralodra.

Kemenkes RI. 2013. Riset Kesehatan Dasar (RISKESDAS). Jakarta: Badan Litbang Kemenkes RI.

Kemenkes RI.2012. Buku Saku Posyandu.Pusat Promosi Kesehatan : Jakarta

Khomsan, Ali. 2007. Sehat dengan Makanan Berkasiat. Jakarta : PT. Kompas Media Nusantara

Khomsan,A.2007.Tehnik Pengukuran Pengetahuan Gizi. Jurusan Gizi Masyarakat dan Sumber Daya Keluarga. Fakultas Pertanian IPB. Bogor.

Mubarak, Wahit Iqbal, dkk. (2007). Promosi Kesehatan Sebuah Pengantar Proses Belajar Mangajar dalam Pendidikan. Yogyakarta: Graha Ilmu.

Murwati dan Lestari, T. 2009. Hubungan Pendidikan Ibu, Umur dan Status Gizi Bayi/Balita dengan Kepatuhan Ibu Berkunjung ke Posyandu. Jurnal Kebidanan. Vol 1 No 1, hal 18-23.

Niven, Neil. 2002. Psikologi Kesehatan untuk Perawat dan Profesional Kesehatan Lain. Jakarta : EGC

Notoatmodjo, S. 2010. Metodologi Penelitian Kesehatan. Jakarta : Rineka Cipta.

Rheihana, Duarsa ABS. (2012). Faktor-faktor yang Berhubungan denganm Partisipasi Ibu untuk Menimbang Balita ke Posyandu. Jurnal Kedokteran YARSI. 20(3). 143-157 (2012).

Sakbaniyah,dkk. 2013. Hubungan Pengetahuan Ibu Balita dengan Kepatuhan Kunjungan Balita ke Posyandu di Desa SumberejoKecamatan Mbranggen Kabupaten Demak. Jurnal Kebidanan Universitas Muhammadiyah Semarang Vol 2 No 1 Tahun 2013

Sugiyarti, R dkk. 2014. Kepatuhan Kunjungan Posyandu dan Status Gizi Balita di Posyandu Karangbendo Banguntapan, Bantul, Yogyakarta. Jurnal Ners and Midwifery Indonesia. Vol.2, No 3, Tahun 2014, hal 141-140. STIKes Alma Ata Yogyakarta 